\title{
Neurotensin Receptor Antagonist Administered during Cocaine Withdrawal Decreases Locomotor Sensitization and Conditioned Place Preference
}

\author{
Klara Felszeghy ${ }^{1,3}$, José Manuel Espinosa ${ }^{1,4}$, Hélène Scarna ${ }^{2}$, Anne Bérod ${ }^{2}$, William Rostène ${ }^{1,5}$ and \\ Didier Pélaprat*, I \\ 'INSERM, U 339, Hôpital Saint-Antoine, Paris Cedex, France; 'Laboratoire de Neuropharmacologie, Faculté de Pharmacie, Université Lyon I, \\ Lyon Cedex, France; ${ }^{3}$ Brain Physiology Research Group, Hungarian Academy of Sciences and Semmelweiss University, Budapest, Hungary
}

\begin{abstract}
Chronic use of psychostimulants induces enduringly increased responsiveness to a subsequent psychostimulant injection and sensitivity to drug-associated cues, contributing to drug craving and relapse. Neurotensin (NT), a neuropeptide functionally linked to dopaminergic neurons, was suggested to participate in these phenomena. We and others have reported that SR 48692, an NT receptor antagonist, given in pre- or cotreatments with cocaine or amphetamine, alters some behavioral effects of these drugs in rats. However, its efficacy when applied following repeated cocaine administration remains unknown. We, therefore, evaluated the ability of SR 48692 , administered after a cocaine regimen, to interfere with the expression of locomotor sensitization and conditioned place preference (CPP) in rats. We demonstrated that the expression of locomotor sensitization, induced by four cocaine injections ( $15 \mathrm{mg} / \mathrm{kg}$, i.p.) every other day and a cocaine challenge I week later, was attenuated by a subsequent 2-week daily administration of SR 48692 (I mg/kg, i.p.). Furthermore, the expression of cocaine-induced CPP was suppressed by a I0-day SR 48692 treatment started after the conditioning period (four $15 \mathrm{mg} / \mathrm{kg}$ cocaine injections every other day). Taken together, our data show that a chronic SR 48692 treatment given after a cocaine regimen partly reverses the expression of locomotor sensitization and CPP in the rat, suggesting that NT participates in the maintenance of these behaviors. Our results support the hypothesis that targeting neuromodulatory systems, such as the NT systems may offer new strategies in the treatment of drug addiction.
\end{abstract}

Neuropsychopharmacology (2007) 32, 260 I-26I0; doi:I0.1038/sj.npp. I30 I382; published online I4 March 2007

Keywords: neurotensin receptor antagonist; cocaine; locomotion; sensitization; conditioned place preference

\section{INTRODUCTION}

Illicit psychostimulant abuse, and in particular cocaine, represents a serious social and health concern in many countries, inducing significant mortality and morbidity (de Lima et al, 2002; O'Brien and Anthony, 2005). There is, however, no effective pharmacological treatment available for cocaine dependence (Gawin and Ellinwood, 1989; Jaffe et al, 1989; Stewart, 2000; de Lima et al, 2002; Soares et al, 2003).

\footnotetext{
*Correspondence: Current address: Dr D Pelaprat, INSERM, U 773, CRB3, Faculté de Médecine Xavier Bichat, BP 416, 16 rue Henri Huchard, 75870 Paris Cedex 18, France, Tel: + 33 I 448563 10, Fax: + 33 | 402588 34, E-mail: pelaprat@bichat.inserm.fr

${ }^{4}$ Current address: Laboratoire PIOM, CNRS UMR550I, 33607 Pessac, France.

${ }^{5}$ Current address: INSERM, U 732, Hôpital Saint-Antoine, 7557| Paris Cedex 12, France.

Received 29 August 2006; revised 27 December 2006; accepted 25 January 2007
}

As for most of the addictive drugs, repeated cocaine exposure in rodents induces enduringly augmented responsiveness to psychostimulants and sensitivity to drugassociated cues, two factors that were proposed to participate in the maintenance of drug craving and relapse (Robinson and Berridge, 1993; Pierce and Kalivas, 1997; Koob et al, 1998). The enhanced response to psychostimulants, a phenomenon termed behavioral sensitization or inverse tolerance (Post and Rose, 1976; Pierce and Kalivas, 1997; Vezina et al, 2002) is associated with a long-lasting increase in the reactivity of the mesolimbic dopaminergic (DAergic) pathway. This pathway originates in the ventral tegmental area (VTA) and belongs to the mesotelencephalic reward/reinforcement system, also referred to as the motivational circuit, or 'motive circuit' (Pierce and Kalivas, 1997; Koob et al, 1998).

The sensitization process encompasses two temporally distinct phases: initiation and expression (Pierce and Kalivas, 1997; Kalivas and Stewart, 1991). Initiation primarily involves action of psychostimulants in the VTA, where the increased extracellular DA enhances glutamate 
release, leading to long-term potentiation-like enhancement of DA neuron activity on repeated drug injections (Borgland et al, 2004; Liu et al, 2005). The expression phase corresponds to the resulting establishment of a new state of the motivational circuit, characterized by an altered balance between the interconnected glutamatergic, GABAergic, peptidergic, and DAergic pathways (Pierce and Kalivas, 1997; Vanderschuren and Kalivas, 2000). As the development of behavioral sensitization is directly related to an increase in drug-motivated behavior, it was suggested to represent an animal model for drug craving in human addicts (Gawin, 1991; Robinson and Berridge, 1993; Bartlett et al, 1997; Ferrario et al, 2005). It may, therefore, be important to develop compounds that could counteract this behavioral effect of the drug.

Given the link between cocaine's addictive properties and DA systems, strategies for the treatment of cocaine addiction were mainly focused on direct targeting of DA transporter or receptors (Morgan et al, 1997; Pilla et al, 1999; de Lima et al, 2002; van den Brink and van Ree, 2003). However, several other neurotransmitter/neuromodulator systems functionally linked to DA neurons within the motivational circuit may also contribute to the complex regulations underlying cocaine dependence (Dewey et al, 1998; de Vries et al, 2001; Sarnyai et al, 2001; Kreek et al, 2002; Beinfeld, 2003; Baptista et al, 2004). Therefore, new approaches investigating the potential of modulatory systems as alternative targets may be of fundamental importance.

The tridecapeptide neurotensin (NT) (Carraway and Leeman, 1973) is a potent modulator of the midbrain DAergic systems (for reviews, see Rostène et al, 1998; Binder et al, 2001; Geisler et al, 2006). Whereas several lines of evidence suggested that NT could represent an endogenous antipsychotic (Kinkead and Nemeroff, 2002), several other data evidenced a psychostimulant-like action of this peptide (Bérod and Rostène, 2002). For instance, similar to systemically injected psychostimulants, intra-VTA NT injection in rodents increased locomotor activity and extracellular DA levels in the nucleus accumbens (Kalivas and Duffy, 1990; Sotty et al, 1998). Moreover, sensitization to the locomotor effect of intra-VTA NT was observed on multiple injections (Kalivas and Duffy, 1990). Furthermore, rats self-administer NT into the VTA (Glimcher et al, 1987), and NT administration into this brain area produces conditioned place preference (CPP) (Glimcher et al, 1984). This paradigm, which measures the preference expressed by an animal for a drug-associated environment, was shown to detect the rewarding properties of virtually all classes of substances abused by humans (Bardo and Bevins, 2000).

In addition to VTA, a role for the medial prefrontal cortex (PFC) in mediating some of the psychostimulant-like effects of NT was reported. For instance, activation of NT receptors in this brain area was found to stimulate midbrain dopamine cell firing (Fatigati et al, 2000; Rompré et al, 1998). Moreover, multiple intraventricular NT injections sensitized rats to the locomotor response induced by systemic amphetamine (Rompré, 1997) or cocaine (Rompré and Bauco, 2006), and these effects were suppressed on lesion of the PFC (Blackburn et al, 2004) or administration of a N-methyl-D-aspartic (NMDA) receptor antagonist (Rompré and Bauco, 2006).
In addition, some other data suggested that endogenous NT might mediate some behavioral effects of psychostimulants. Pretreatment with an antagonist of the high-affinity NT receptor 1 (NTS1), SR 48692 (Gully et al, 1993), attenuated the locomotor response to an acute cocaine injection (Betancur et $a l, 1998$ ) and delayed the development of cocaine sensitization (Horger et al, 1994). Furthermore, coadministration of SR 48692 or its analogue SR 142948A (Gully et al, 1997) and amphetamine blunted locomotor sensitization induced by the latter drug (Rompré and Perron, 2000; Panayi et al, 2002, 2005).

However, these experiments did not evaluate the efficacy of NTS1 antagonists when applied following repeated drug administration. In the present study, we investigated the ability of SR 48692, when administered to rats during the withdrawal period, to attenuate the expression of cocaineinduced locomotor sensitization and CPP.

\section{MATERIALS AND METHODS}

\section{Animals}

Male Sprague-Dawley rats (OFA strain) (Iffa-Credo, France), weighing $220-240 \mathrm{~g}$ at the beginning of the experiments, were housed five per cage with free access to food and water, in a temperature $\left(22^{\circ} \mathrm{C}\right)$-controlled room under a $12 \mathrm{~h}$ light/dark cycle. Experiments were always performed during the light phase. All procedures were carried out in accordance with the European Community Council Directive for the care and use of laboratory animals.

\section{Drugs}

SR 48692 (2-(1-[7-chloro-4-quinolinyl]-5-[2,6-dimethoxyphenyl]-1H-pyrazol-3-)carbonylamino-adamantane-2-carboxylic acid) (generous gift from Sanofi-Aventis, France) was suspended $(1 \mathrm{mg} / \mathrm{ml})$ with Tween 80 (Cis-Bio International, France) $(0.1 \%)$ in saline and injected through intraperitoneal (i.p.) route at the dose of $1 \mathrm{mg} / \mathrm{kg}$ (Betancur et al, 1998; Panayi et al, 2002). Control rats received vehicle $(0.1 \%$ Tween 80 in saline). Cocaine hydrochloride (COOPER, Melun, France) was dissolved $(15 \mathrm{mg} / \mathrm{ml})$ in saline and injected i.p. at the dose of $15 \mathrm{mg} / \mathrm{kg}$, calculated as free base. Controls for cocaine treatment received saline i.p. injections.

\section{Behavioral Measurements}

Locomotor activity. Locomotor activity was monitored in Plexiglas cages $(30 \times 18 \times 18 \mathrm{~cm})$ equipped with two series of infrared photobeams positioned 4 and $12 \mathrm{~cm}$ above the floor, respectively (Imétronic, France). Vertical activity was quantified by the number of superior photobeam breaks induced by rearing of the animal. Horizontal locomotion was estimated by determination of consecutive inferior photobeam breaks (crossovers). The number of rearings and crossovers was cumulated over $5 \mathrm{~min}$ intervals.

Conditioned place preference. The CPP apparatus consisted of two conditioning compartments (one black with smooth floor and one striped with rough floor) of equal size $(45 \times 45 \times 30 \mathrm{~cm})$, both accessible from an exterior central 
choice chamber $(36 \times 18 \times 30 \mathrm{~cm})$, as described by Valverde et al (1997). Inserting removable partitions could isolate each conditioning compartment from the central choice chamber. Compartments were lighted with separate bulbs (100 lux in each compartment). The position of the rats was recorded through a video camera (Videotrack II 2.12 version, Viewpoint, Lyon, France) and the time spent in the conditioning compartments and central chamber was measured.

The place conditioning procedure consisted of three phases: preexposure, conditioning, and CPP test.

Preexposure: To assess the primary preference of animals, rats were placed on day 1 in the central choice chamber and were given free access to the entire apparatus for $20 \mathrm{~min}$. For each rat, the time spent in each conditioning compartment (black or striped) was calculated as a percentage of the time spent in both compartments (black + striped sum). Rats showing a strong preference (more than $75 \%$ of the black + striped sum) or aversion (less than $25 \%$ of the black + striped sum) for one conditioning compartment were discarded. After the session, the remaining animals were randomly assigned to both an experimental group and a 'drug-paired compartment', in a counterbalanced fashion: the black compartment for half of the rats and the striped compartment for the other half (Mueller and Stewart, 2000). It should be noticed that one drug-paired compartment and one 'nondrug-paired compartment' were defined for all rats. The former compartment was, therefore, not called 'cocaine-paired compartment', as it could be associated with either cocaine or saline injection depending on the experimental group (see next paragraph). The data from the preexposure day (presented in Figure 4a) were calculated after completion of this double-randomization procedure.

Conditioning: The conditioning trials were performed from day 2 to day 8 . A single session was performed per day. On days 2, 4, 6, and 8 , rats received either cocaine (cocaine groups) or saline (saline groups) and were immediately confined to their assigned drug-paired compartment for $20 \mathrm{~min}$. On days 3, 5, and 7, all rats were administered with saline and immediately confined to their assigned nondrug-paired compartment for $20 \mathrm{~min}$.

CPP test: Animals were placed in the central choice chamber, with free access to each compartment for $20 \mathrm{~min}$. Expression of cocaine-induced CPP was evidenced by an increased amount of time spent by the animal in the drugpaired compartment, at the expense of that spent in the nondrug-paired compartment. Data thus expressed not only as the time spent in the drug-paired compartment, but also as the difference between the times spent in the drug-paired and in the nondrug-paired compartments. No injection was administered on the day of the CPP test.

\section{Experimental Design}

Experiment 1: effect of a 2-week SR 48692 treatment on locomotion induced by cocaine challenges in sensitized rats. It was previously demonstrated that establishment of the behavioral sensitization expression phase proceeded over at least 1 week after discontinuing the initial repeated cocaine injection procedure (Pierce and Kalivas, 1997). In the present experiment, sensitization of locomotor activity was therefore initiated by four injections of cocaine (15 mg/ $\mathrm{kg}$, i.p., $n=40$ rats), one injection every other day (days 1,3 , 5 , and 7), followed by 1-week drug withdrawal and a cocaine challenge (15 mg/kg, i.p.) on day 14 . Expression of sensitization was evaluated by administrating the same dose of cocaine on days 21 and 28. Cocaine was administered in the home cage on days 3 and 5, and in the activity cage on days $1,7,14,21$, and 28 . On these days, rats were placed in the activity cages for a $30 \mathrm{~min}$ period before the cocaine injection; locomotion was recorded during this period and during 1 hour following injection of the drug.

The effect of SR 48692 ( $1 \mathrm{mg} / \mathrm{kg}$, i.p., $n=20$ ) on cocaineinduced locomotion in sensitized animals was investigated by injecting the antagonist once daily from day 15 to day 28 . Control rats $(n=20)$ received vehicle $(0.1 \%$ Tween 80 in saline) instead of SR 48692. The SR 48692 (or vehicle) injections were administered in the home cage. On days 21 and 28 , rats were left in the home cage for $30 \mathrm{~min}$ after the SR 48692 or vehicle injection and were placed in the activity cages for another $30 \mathrm{~min}$ period before the cocaine injection. Locomotion was recorded during this period and during 1 hour following injection of the drug.

Although doses of $80-300 \mu \mathrm{g} / \mathrm{kg}$ were found to be effective in different paradigms (Rompré and Perron, 2000; Horger et al, 1994), we previously found that daily treatments with $1 \mathrm{mg} / \mathrm{kg}$, but not $100 \mu \mathrm{g} / \mathrm{kg}$, attenuated locomotion induced by acute cocaine (Betancur et al, 1998) and locomotor sensitization to amphetamine in rats (Panayi et al, 2002). We, therefore, chose the dose of $1 \mathrm{mg} / \mathrm{kg}$ for the present study.

Experiment 2: effect of a 2-week SR 48692 treatment on cocaine-induced locomotor activity in saline preexposed animals. The experimental protocol was similar to that performed in Experiment 1, except that rats $(n=24)$ received saline injections (i.p.) instead of cocaine injection on days $1,3,5,7,14$, and 21 . The only cocaine injection (15 mg/kg, i.p.) was administered on day 28. In keeping with the procedure followed in Experiment 1, saline was administered in the home cage on days 3 and 5, whereas saline injections on days $1,7,14$, and 21 as well as the cocaine injection on day 28 were administered in the activity cage. On these days, rats were placed in the activity cages for a $30 \mathrm{~min}$ period before the saline (or cocaine for day 28) injection and their locomotion was recorded for 1 hour. Daily administration of SR 48692 ( $1 \mathrm{mg} / \mathrm{kg}$, i.p., $n=12)$ or vehicle $(n=12)$ was performed in the home cage from day 15 to day 28, as described in Experiment 1.

Experiment 3: effect of SR 48692 administered after the conditioning period on the expression of cocaine-induced $C P P$. Animals were selected following preexposure to the CPP apparatus and randomly assigned to either of four groups as follows: sal $+\mathrm{VEH}$ receiving saline instead of cocaine and vehicle instead of SR $48692(n=14)$; coc $+\mathrm{VEH}$ receiving cocaine and vehicle $(n=14)$, sal + SR receiving saline and SR $48692(n=13)$, and $\operatorname{coc}+$ SR receiving cocaine and SR $48692(n=14)$. 
Rats were then conditioned as described in the "Behavioral measurements' section. On days $2,4,6$, and 8 , rats received either cocaine $(15 \mathrm{mg} / \mathrm{kg}$, i.p., for $\operatorname{coc}+\mathrm{VEH}$ and coc $+\mathrm{SR}$ groups) or saline (for sal $+\mathrm{VEH}$ and sal $+\mathrm{SR}$ groups) and were immediately confined to their assigned drug-paired compartment for $20 \mathrm{~min}$. On days 3, 5, and 7, all rats were administered with saline and immediately confined to their assigned nondrug-paired compartment for $20 \mathrm{~min}$

Daily injections of either SR 48692 (1 mg/kg, i.p., sal + SR and coc + SR groups) or vehicle (sal + VEH and coc + VEH groups) were then administered in the home cage, from day 9 to day 18. On day 17, a saline injection (all rats) was administered in the home cage $30 \mathrm{~min}$ after the ninth SR48692 or vehicle injection. On day 18 , either a cocaine $(15 \mathrm{mg} / \mathrm{kg}$, i.p., coc $+\mathrm{VEH}$ and coc + SR groups) or a saline (sal + VEH and sal + SR groups) injection was administered in the home cage, $30 \mathrm{~min}$ after the tenth SR 48692 (or vehicle) injection. CPP expression was measured on day 19.

It was previously reported that expression of cocaineinduced CPP could be detected as soon as $24 \mathrm{~h}$ after the conditioning phase (Dewey et al, 1998; Baker et al, 1998). As the aim of this study was to evaluate the effects of SR 48692 when this compound was administered after acquisition of the cocaine-induced behaviors, we verified in a pilot experiment that preference for the cocaine-paired environment was already detected when the CPP test was performed on day 9 (not shown).

\section{Statistical Analysis}

The locomotor responses on days 1, 7, and 14 were analyzed by a one-way analysis of variance (ANOVA) for repeated measures. The locomotor responses observed in the presence or in the absence of SR 48692 on days 21 and 28 were compared through a two-way ANOVA with one within-subject factor (Time) and one between-subject factor (Treatment: SR 48692 or vehicle). The cumulated activities recorded during the $60 \mathrm{~min}$ period following cocaine administration were analyzed with Student's $t$-test. CPP data obtained on day 19 were analyzed by a two-way ANOVA (Drug condition: cocaine or saline; Treatment condition: SR 48692 or vehicle). In all experiments, post hoc comparisons were performed using Newman-Keuls test. Differences at $p<0.05$ were considered as significant.

\section{RESULTS}

Two-Week SR 48692 Administration after a Cocaine Regimen Decreases Locomotion Induced by Cocaine Challenge in Sensitized Rats (Experiment 1)

Rats were sensitized to cocaine through four injections of the drug, followed by 1-week drug-free period and a subsequent cocaine challenge (Figures $1 \mathrm{a}, \mathrm{b}$ and $2 \mathrm{a}, \mathrm{b}$ ). The first cocaine injection (day 1) induced a moderate increase in horizontal locomotion (Figure 1a) and no significant alteration in vertical activity (Figure 2a). Following three additional cocaine injections (day 7) and a subsequent cocaine challenge 1 week later (day 14), significant increases in both horizontal (Figure $1 \mathrm{a}$ and $\mathrm{b}$ ) and vertical (Figure $2 \mathrm{a}$ and $\mathrm{b}$ ) activity responses were observed (Figure 1b: one-way ANOVA: $F_{2,78}=10.4$, $p<0.001$; Figure 2b: one-way ANOVA: $F_{2,78}=13.3$, $p<0.001)$. The enhancement of the locomotor effects of cocaine on days 7 and 14 compared to day 1 indicated that this experimental paradigm induced motor sensitization to the drug.

In vehicle-treated rats, high horizontal and vertical activities were also observed following cocaine challenges administered on day 21 (Figures $1 \mathrm{c}$ and $2 \mathrm{c}$ ) and day 28 (Figures $1 \mathrm{~d}$ and $2 \mathrm{~d}$ ), reflecting a maintained expression of sensitization throughout this 1 -month time period. Daily injection of $1 \mathrm{mg} / \mathrm{kg}$ SR 48692 for 1 week from day 15 did not alter the activity induced by a cocaine challenge on day 21 (Figures 1c and 2c). However, a 2-week SR 48692 administration decreased both the horizontal (Figure 1d) and vertical (Figure 2d) activities induced by a cocaine challenge on day 28 (two-way ANOVAs: Figure 1d: Treatment: $F_{1,407}=6.25, p<0.05$; Figure $2 \mathrm{~d}$ : Treatment: $\left.F_{1,407}=5.24, p<0.05\right)$. Significant differences between SR 48692- and vehicle-treated rats were obtained from 10 to 35 min following the cocaine injection (post hoc analysis, Newman-Keuls test).

The cocaine treatment did not alter the horizontal or vertical locomotor activity recorded during the $30 \mathrm{~min}$ period preceding the injection of the drug (Figures 1a, c, d and 2a, c, d). Furthermore, neither the 1-week nor the 2-week SR 48692 treatment alone altered the locomotor activity observed within this initial $30 \mathrm{~min}$ period on days 21 and 28 (Figures $1 \mathrm{c}, \mathrm{d}$ and $2 \mathrm{c}, \mathrm{d}$ ).

\section{Two-Week SR 48692 Administration does not Alter Cocaine-Induced Locomotor Activity in Saline Preexposed Animals (Experiment 2)}

In this experiment, we applied the same experimental procedure as in Experiment 1, except that the cocaine injections on days $1,3,5,7,14$, and 21 were replaced by saline injections, the first cocaine injection occurring on day 28 (Figure 3, lower panel). As shown in Figure 3, a 2-week SR $48692(1 \mathrm{mg} / \mathrm{kg})$ treatment started from day 15 altered neither the horizontal (Figure 3a) nor the vertical (Figure $3 \mathrm{~b}$ ) activities induced by this acute cocaine injection.

\section{SR 48692 Administered for 10 Days after the Conditioning Phase Attenuates Cocaine-Induced CPP (Experiment 3)}

In this experiment, SR 48692 or vehicle were administered daily for 10 days (9-18 days) after the conditioning phase of the CPP paradigm. CPP was measured on day 19, 24 hours after an additional cocaine challenge (Figure 4).

In the preexposure test (day 1, Figure 4a), all groups of rats spent similar time exploring the assigned drug-paired compartment. Moreover, no preference for a given compartment was detected in any group (differences between times spent in the drug-paired and nondrug-paired compartments: sal + VEH: $8.2 \pm 30.5 \mathrm{~s} ; \quad$ coc + VEH: $37.2 \pm$ $37.7 \mathrm{~s} ; \mathrm{sal}+\mathrm{SR}: 0.3 \pm 24.5 \mathrm{~s} ; \operatorname{coc}+\mathrm{SR}: 18.7 \pm 27.1 \mathrm{~s}$ for all values, nonsignificantly different from zero).

On day 19 (Figure 4b), a two-way ANOVA for drug condition (cocaine or saline) and treatment condition 


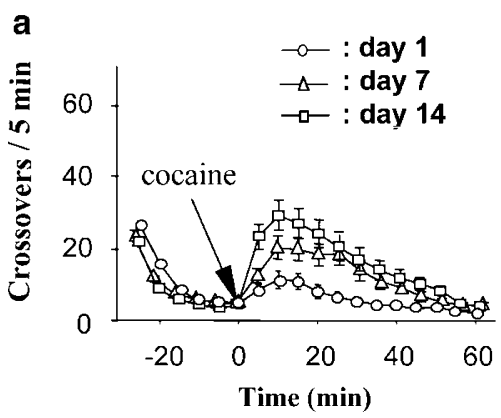

b
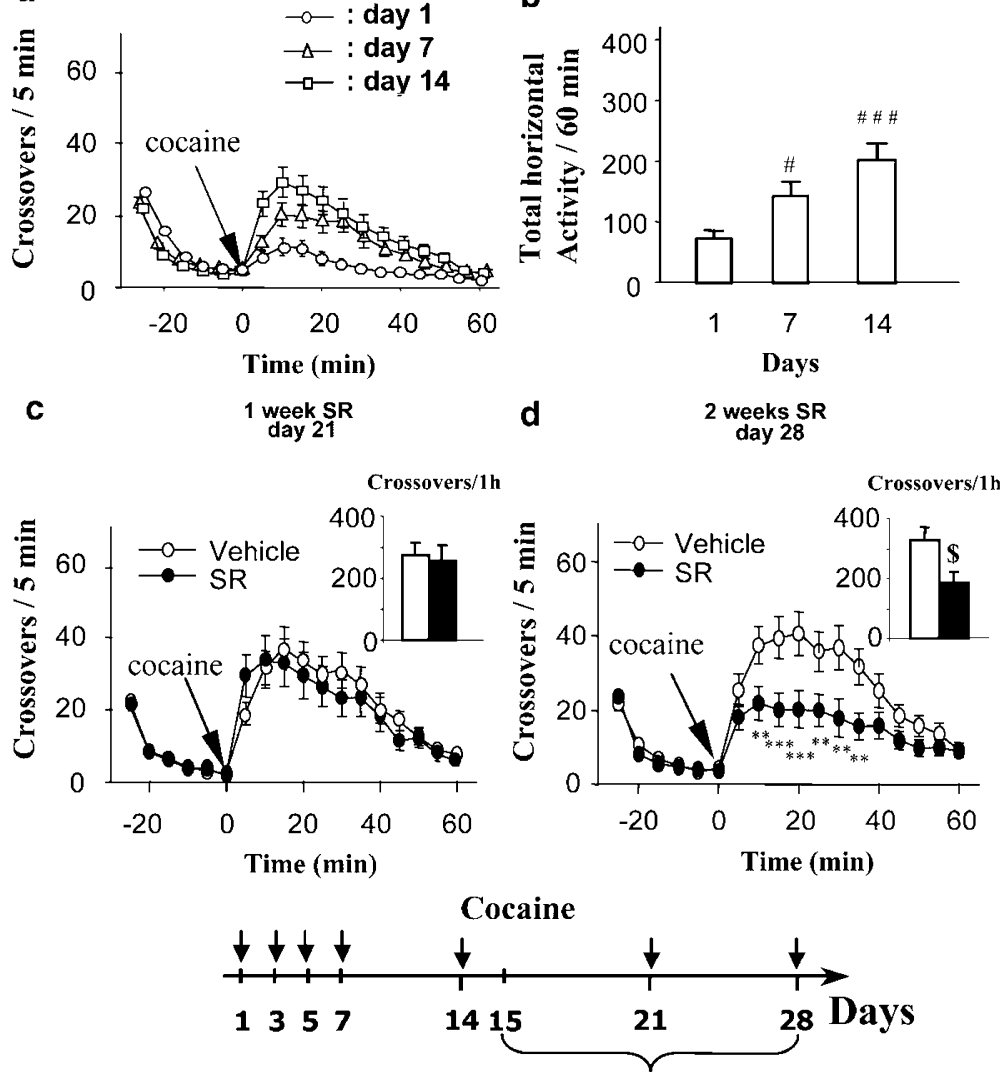

Daily SR48692 treatment

Figure I Experiment I: A 2-week administration of SR 48692 during the withdrawal period attenuates expression of horizontal locomotor sensitization in cocaine pre-exposed rats. Rats $(n=40)$ received cocaine injections $(15 \mathrm{mg} / \mathrm{kg}$, i.p.) on days I, 3, 5, 7, and I4. Daily administration of SR 48692 (I mg/kg, i.p., $n=20)$ or vehicle $(n=20)$ was performed from day 15 to day 28. Cocaine challenges $(I 5 \mathrm{mg} / \mathrm{kg}$, i.p.) were performed on days $2 \mid$ and 28 . Data represent mean \pm SEM of crossovers summed either over $5 \mathrm{~min}(a, c, d)$ or over the 60 min period following cocaine injection (b, $c$ inset, $d$ inset). (b) ${ }^{\#} p<0.05$, $\# \# \#<0.00$ I vs day I (one-way ANOVA, Newman-Keuls). (d) $* * p<0.0$ I, **** $p<0.00$ I vs vehicle-treated rats (two-way ANOVA, Newman-Keuls). $d$ inset: ${ }^{\$} p<0.05$ vs vehicle-treated rats (Student's t-test).

(SR 48692 or vehicle) indicated a significant effect of the drug factor $\left(\mathrm{F}_{1,51}=14.12, p<0.001\right)$ and a significant drug $\times$ treatment interaction $\left(\mathrm{F}_{1,51}=4.26, p<0.05\right)$. Newman-Keuls post hoc analysis indicated that the time spent by the coc + VEH group in the drug-paired compartment was significantly higher than that spent by the sal + VEH group $(p<0.001)$. In addition, the time spent by the coc + SR group in the drug-paired compartment was significantly lower than that observed for the coc + VEH group $(p<0.05)$, but did not differ from that obtained for the sal + SR group. Similarly, when data were expressed as the differences between times spent in drug-paired and nondrug-paired compartments, a significant effect of the drug factor $\left(\mathrm{F}_{1,51}=16.37, p<0.001\right)$ and a significant drug $\times$ treatment interaction $\left(\mathrm{F}_{1,51}=4.72, p<0.05\right)$ were found by two-way ANOVA. Newman-Keuls post hoc analysis showed that the time difference was significantly higher for the coc $+\mathrm{VEH}$ group than for the sal + VEH group $(149.1 \pm 35.9$ vs $-61.6 \pm 26.6 \mathrm{~s}, p<0.001)$, indicating that the increase in time spent in the drug-paired compartment by the coc + VEH group was obtained at the expense of that spent in the nondrug-paired compartment. By contrast, the value obtained for the coc + SR group $(29.8 \pm 24.6 \mathrm{~s})$ did not differ from that obtained for the sal + SR group $(-33.6 \pm 30.1 \mathrm{~s})$ and was significantly lower than that observed for the coc + VEH group $(p<0.05)$.

These data indicated that a daily treatment with SR 48692 during the 10-day withdrawal period decreased the expression of CPP. No significant effect of SR 48692 alone was seen in rats treated with saline during the whole procedure (comparison sal + VEH vs sal + SR) (Figure $4 \mathrm{~b}$ ).

\section{DISCUSSION}

Taken together, the present data show that a 2-week treatment with SR 48692 given after a cocaine regimen reduced locomotion induced by a cocaine challenge in sensitized rats. Furthermore, SR 48692 treatment administered after the cocaine conditioning period attenuated the expression of cocaine-induced CPP. Therefore, this compound is not only efficient to decrease the long-term effects of cocaine when applied before a cocaine treatment, as reported previously (Horger et al, 1994; Betancur et al, 1998), but also when administered following repeated drug exposure.

It is unlikely that the decrease in horizontal and vertical locomotion observed following 2-week SR 48692 adminis- 

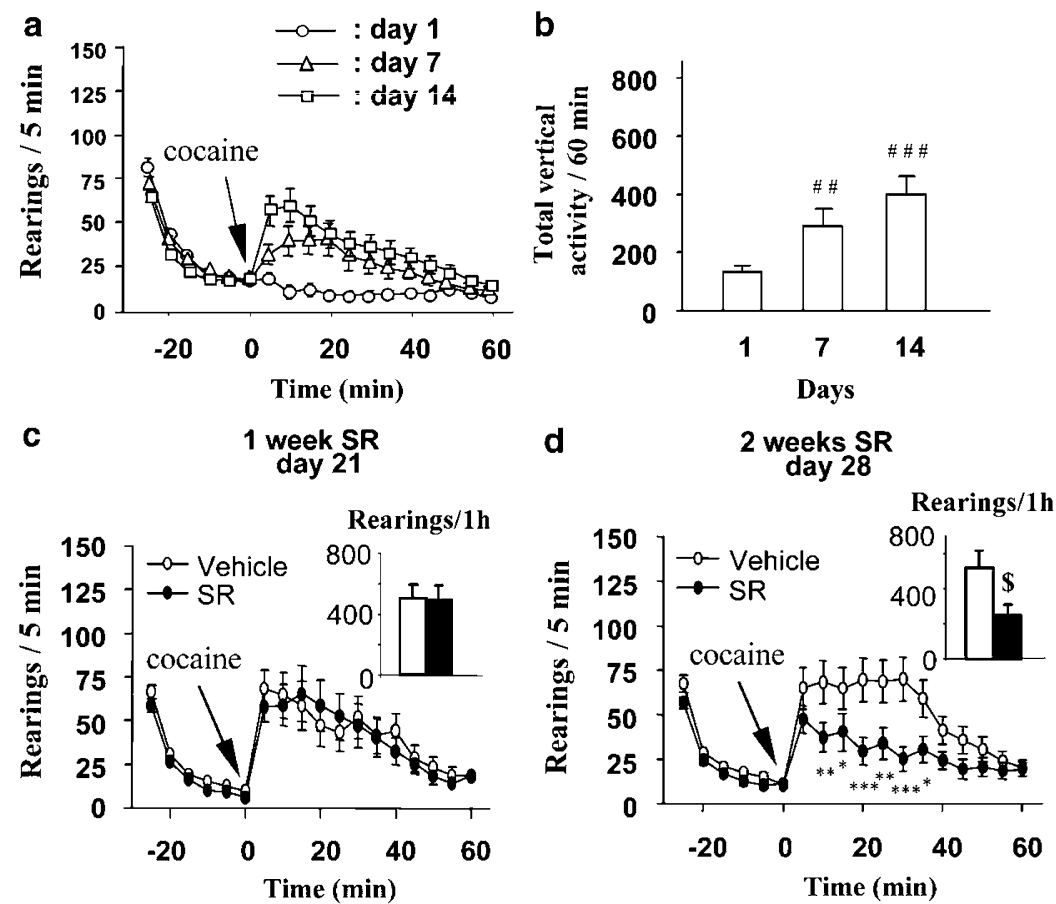

Figure 2 Experiment I: A 2-week administration of SR 48692 during the withdrawal period attenuates expression of vertical locomotor sensitization in cocaine preexposed rats. Rats $(n=40)$ received cocaine injections ( $15 \mathrm{mg} / \mathrm{kg}$, i.p.) on days I, 3, 5, 7, and I4. Daily administration of SR 48692 (I mg/kg, i.p., $n=20)$ or vehicle $(n=20)$ was performed from day 15 to day 28. Cocaine challenges $(15 \mathrm{mg} / \mathrm{kg}$, i.p.) were performed on days 21 and 28 (see Figure $\mid$, lower panel, for the experimental time schedule). Data represent mean + SEM of rearings summed either over 5 min ( $a, c, d)$ or over the 60 min period following cocaine injection (b, $c$ inset, $d$ inset). (b) ${ }^{\# \#} p<0.0$ I, \#\#\# $<0.00$ I vs day I (one-way ANOVA, Newman-Keuls). (d) * $p<0.05, * * p<0.0$ I, **** $p<0.00$ I vs vehicle-treated rats (two-way ANOVA, Newman-Keuls); $d$ inset: ${ }^{\$} p<0.05$ vs vehicle-treated rats (Student's $t$-test).
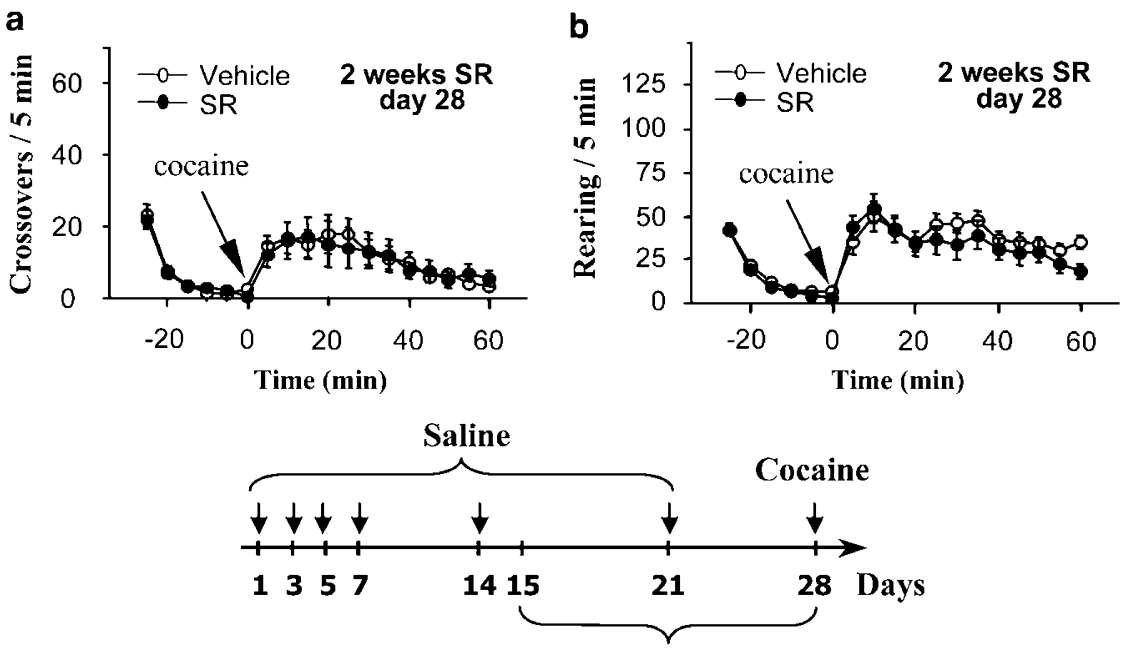

Daily SR48692 treatment

Figure 3 Experiment 2: A 2-week administration of SR 48692 does not alter cocaine-induced locomotor activity in saline preexposed rats. The experimental protocol was similar to that performed in Experiment I. However, in this experiment, rats $(n=24)$ received saline injections (i.p.) on days I, 3 , $5,7,14$, and 21 , and a single cocaine challenge $(15 \mathrm{mg} / \mathrm{kg}$, i.p.) was performed on day 28. Daily administration of SR $48692(\mathrm{I} \mathrm{mg} / \mathrm{kg}$, i.p., $n=12)$ or vehicle $(n=12)$ was performed from day 15 to day 28. Data represent mean \pm SEM of crossovers (a) or rearings (b) summed over 5 min.

tration was owing to the occurrence of focused stereotypies, as these behaviors generally produce an early inhibition of locomotion followed by a rebound increase, thereby resulting in a biphasic temporal profile of locomotion (Ferrario et al, 2005) which was not observed in the present study. This is in line with previous results demonstrating that NT receptor blockade (1) counteracted both horizontal and vertical activities, but did not affect stereotyped behaviors induced by psychostimulants (Betancur et al, 1998; Panayi et al, 2002) and (2) selectively modulated the 

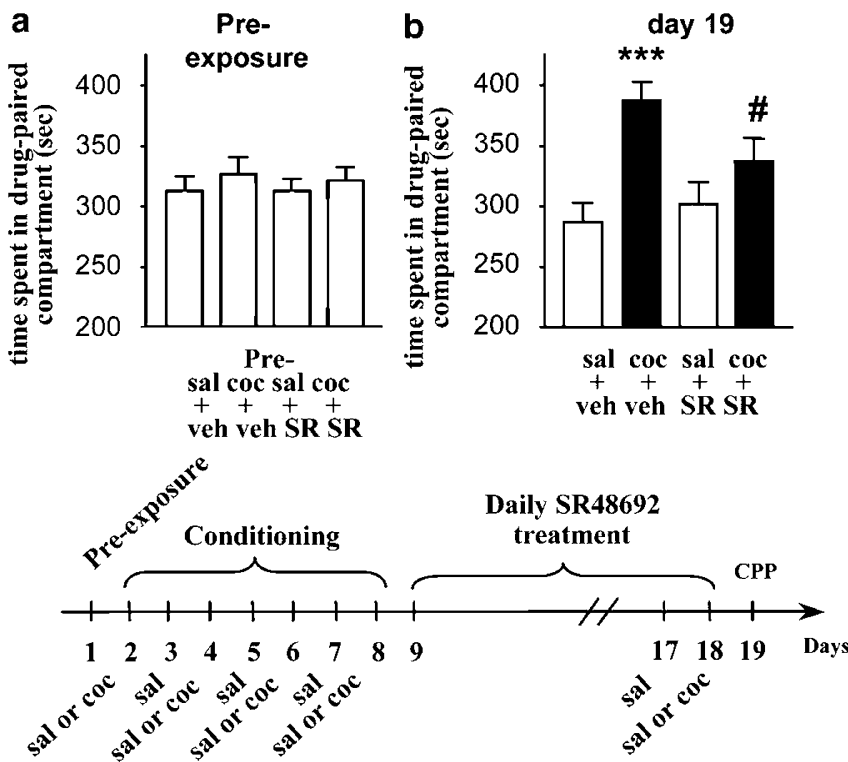

Figure 4 Experiment 3: SR 48692 administration during the withdrawal period decreases expression of cocaine-induced CPP. Rats were tested for CPP on day I (preexposure), followed by a conditioning period with i.p. injections of either saline (sal) or cocaine ( $\mathrm{coc}, 15 \mathrm{mg} / \mathrm{kg}$ ) until day 8 , as indicated (lower panel). Vehicle (veh) or SR 48692 (SR, I mg/kg) were administered i.p. from day 9 to day |8. A cocaine challenge ( $15 \mathrm{mg} / \mathrm{kg}$, i.p.) was then applied on day 18, and CPP was assessed on day 19. The coc + veh $(n=14)$ and coc + SR $(n=14)$ groups received cocaine on days $2,4,6$, 8 , and I8, and saline on days $3,5,7$, and 17. The sal + veh $(n=\mid 4)$ and $\mathrm{sal}+\mathrm{SR}(n=13)$ groups always received saline instead of cocaine. Data represent means \pm SEM of time spent in drug-paired compartment. ${ }^{*} * * * * 0.00$ I vs sal + veh-treated rats; ${ }^{\#} p<0.05$ vs coc + veh-treated rats (two-way ANOVA, Newman-Keuls).

mesolimbic DAergic system compared to the nigrostriatal system involved in focused stereotypies (Ervin et al, 1981; Ford and Marsden, 1990).

Whereas it revealed to be efficient on cocaine-induced locomotion in sensitized rats, the 2-week SR48692 treatment did not alter cocaine-induced locomotion when tested on saline preexposed animals under the same experimental conditions. This observation suggests that the effect of the SR48692 treatment in sensitized rats was not because of a mere blunting of cocaine-induced locomotion. Such a lack of effect of the SR 48692 treatment on saline preexposed animals lies in contrast with our preceding data, showing that a 1-week pretreatment with the same dose of SR 48692 attenuated both horizontal and vertical locomotion induced by acute cocaine (Betancur et al, 1998). However, the present experiment was performed under different conditions, as the saline preexposed animals were habituated to the locomotion chambers, which was not the case for the naive rats in our previous study (Betancur et al, 1998). Interestingly, in the latter study, the SR 48692 pretreatment also decreased the vertical locomotion induced by novelty, observed within the $30 \mathrm{~min}$ period before the acute cocaine injection. According to these considerations, it might be suggested that the ability of SR 48692 to alter locomotion induced by acute cocaine partly depends on the novelty of the associated environment.

Attenuation of sensitized locomotion following SR 48692 treatment suggests that endogenous NT participates in the maintenance of this behavior. As it was previously reported that NT also participated in the initiation of cocaine sensitization (Horger et al, 1994), one can, therefore, propose that NT may be involved in several steps of the sensitization process generated by this drug. Furthermore, attenuation of CPP expression following SR 48692 treatment suggests that endogenous NT participates in the maintenance of the conditioned response to cocaine. Interestingly, it was previously demonstrated that injections of SR 48692 before amphetamine challenges could attenuate the conditioned component of locomotor sensitization to amphetamine in mice (Costa et al, 2001). However, in the present study, rats were not only injected with cocaine either in the test cage (days 1 and 7) or in the home cage (days 3 and 5), but they were also habituated to the test cage 30 min before each cocaine injection. These manipulations are known to degrade considerably the ability of contextual stimuli to acquire conditioned stimulus properties (see, for example, Crombag et al, 2001). Therefore, it is highly probable that, under our experimental conditions, conditioning did not contribute to the sensitized locomotor response to cocaine. This hypothesis is further supported by the lack of effect of the cocaine treatment on the locomotion observed during the initial 30 min period.

Numerous studies showed that most of the SR 48692 effects could be explained by blockade of the NTS1 subtype of NT receptors (Kitabgi, 2002). This receptor is present in most of the structures of the motivational circuit, such as the VTA, nucleus accumbens, prefrontal cortex (PFC), central amygdala and the ventral pallidum (Boudin et al, 1996; Rostène et al, 1998; Binder et al, 2001; Radja et al, 2006; Geisler and Zahm, 2006). Both environmental cuesdependent and cues-independent enduring behavioral changes induced by psychostimulants are related to sustained alterations in the functional balance between components of this circuit (Pierce and Kalivas, 1997; Baker et al, 1998; Dewey et al, 1998). As SR48692 was injected systemically and could potentially reach all brain regions, the effects of the SR48692 treatment observed here on sensitized locomotion and CPP might result from a global interruption of the NT input to all these brain areas.

Alternatively, the action of SR48692 might primarily be due to the blockade of the NT input in only some of these structures. Indeed, microinjection studies revealed that NT could exert opposite actions on DA systems, depending on the brain area. Whereas intraaccumbens NT or SR 48692 injections revealed an attenuating role of exogenous as well as endogenous NT on DA transmission in this region, both intra-VTA and intra-PFC NT injections resulted in activation of DAergic systems (for reviews, see Kinkead and Nemeroff, 2002; Bérod and Rostène, 2002). As the sensitized state of the motivational circuit encompasses augmented activities of both the DA mesolimbic pathway and its glutamatergic afferents arising from PFC (Pierce and Kalivas, 1997), it could be postulated that the effect of SR 48692 on the sensitization process is primarily owing to the sustained interruption of the NT input to VTA and/or PFC.

Indeed, some arguments could favor the hypothesis of a preferential role of PFC over VTA in mediating the attenuation of both sensitized locomotion and CPP by SR 49682. For instance, whereas intra-VTA NT injection sensitized rats to the locomotor effect of NT but not to 
systemic amphetamine (Elliott and Nemeroff, 1986), multiple intraventricular NT injections sensitized the animals to the locomotor response induced by amphetamine (Rompré, 1997) or cocaine (Rompré and Bauco, 2006) and these effects were suppressed on lesion of the PFC (Blackburn et al, 2004) or systemic administration of a NMDA receptor antagonist (Rompré and Bauco, 2006). Furthermore, attenuation of cocaine-induced CPP by SR 48692 suggests that this compound counteracted the conditioned responses to cocaine, which was previously suggested to be dependent on NMDA receptors and PFC activation (Tzschentke, 2000).

In the present study, we observed that a 2-week SR 48692 treatment was required to decrease cocaine-induced locomotor sensitization. Long-term pre- or cotreatments with SR 48692 were also needed to reduce initiation of cocaine or amphetamine sensitization, when this antagonist was administered systemically (Horger et al, 1994; Panayi et al, 2002). These delays observed for obtaining an effect of SR 48692 suggest that by contrast with glutamate or dopamine (Pierce and Kalivas, 1997; Baker et al, 1998; Li et al, 1999; Kreek et al, 2002) NT does not act as a direct link but rather as a modulator in mediating these behavioral effects of the psychostimulants. Such an involvement of NT would be consistent with the view of a modulatory role of neuropeptides, compared to that of classical neurotransmitters. These data are also consistent with the temporal aspects of the SR 48692-induced alterations in the mesolimbic DA transmission, several weeks of treatment with this antagonist being needed to decrease the number of spontaneously active DA neurons in the VTA (Santucci et al, 1997) and the basal extracellular DA levels in the nucleus accumbens (Azzi et al, 1998).

An alternate hypothesis is that the delayed responses to NT antagonists on systemic administration reflect the dual involvement of NT in the modulation of DA transmission, through a temporary masking of the antagonist action in some structures, such as the VTA or PFC, by blockade of NT receptors in the other brain areas. This hypothesis was recently proposed from data obtained with another NT receptor antagonist, SR 142948A, demonstrating that a single intra-VTA administration of this compound before an amphetamine injection was sufficient to counteract the induction of behavioral sensitization to this psychostimulant (Panayi et al, 2005), whereas a long-term treatment was required on systemic administration (Panayi et al, 2002).

Interestingly, SR48692 itself was reported to have a dual action on NT receptors. In addition to NTS1, this compound was shown to interact with the NTS2 subtype of NT receptors, although with a 100 -fold lower affinity (Gully et al, 1993). By contrast with its antagonistic properties toward NTS1, SR48692 behaved as an agonist on NTS2 (Vita et al, 1998; Yamada et al, 1998; Sarret et al, 2002; Gendron et al, 2004). Under our experimental conditions involving repeated administration of $1 \mathrm{mg} / \mathrm{kg}$ SR 48692, an involvement of NTS2 cannot be excluded. In such a hypothesis, the delay needed to observe the effect of the antagonist might therefore reflect the time required for completing the complex regulations resulting from the perturbations in these two receptor systems.

The dual involvement of NT might also explain why an attenuation of the acute effects of cocaine or amphetamine could also be evidenced following administration of NT agonists (Richelson et al, 2003). It was recently shown that these agonists did not display rewarding properties by themselves (Fantegrossi et al, 2005). Therefore, future studies might paradoxically reveal that acting on NT systems through either agonists or antagonists could be of potential use for the treatment of addiction. However, the ability of NT agonists to counteract cocaine effects when applied following repeated drug administration was not yet demonstrated.

In conclusion, the results reported in the present study show that targeting a modulator of DAergic systems like NT may counteract some behavioral effects of cocaine related to drug addiction, such as locomotor sensitization and CPP. SR 48692 was recently tested in human as a potential antipsychotic drug (Meltzer et al, 2004). Although no clear activity was demonstrated on schizophrenia or schizoaffective disorders in the latter study, this compound was shown to be devoid of adverse effects or intrinsic toxicity over 6 weeks of administration (Meltzer et al, 2004). Further evaluation of compounds of this class could be of interest in the search of new therapeutics for the treatment of psychostimulant drug addiction.

\section{ACKNOWLEDGEMENTS}

We thank Dr D Gully (Sanofi-Aventis laboratories, France) for the generous gift of SR 48692. This work was supported by the Institut de la Santé et de la Recherche Médicale (INSERM), the Universite Claude Bernard Lyon I, and the National Institute on Drug Abuse USPS NIH DA 15207 (Suppl). K Felszeghy was supported by an INSERM grant for foreign senior researchers. We also thank R Rambur for artwork.

\section{REFERENCES}

Azzi M, Betancur C, Sillaber I, Spanagel C, Rostène W, Bérod A (1998). Repeated administration of the neurotensin receptor antagonist SR 48692 differentially regulates mesocortical and mesolimbic dopaminergic systems. J Neurochem 71: 1158-1167.

Baker DA, Fuchs RA, Specio SE, Khroyan TV, Neisewander JL (1998). Effects of intraaccumbens administration of SCH-23390 on cocaine-induced locomotion and conditioned place preference. Synapse 30: 181-193.

Baptista MA, Martin-Fardon R, Weiss F (2004). Preferential effects of the metabotropic glutamate $2 / 3$ receptor agonist LY379268 on conditioned reinstatement versus primary reinforcement: comparison between cocaine and a potent conventional reinforcer. J Neurosci 24: 4723-4727.

Bardo MT, Bevins RA (2000). Conditioned place preference: what does it add to our preclinical understanding of drug reward? Psychopharmacology 153: 31-43.

Bartlett EB, Chapman B, Hallin E, Angrist B (1997). Selective sensitization to the psychosis-inducing effects of cocaine: a possible marker for addiction relapse vulnerability? Neuropsychopharmacology 16: 77-82.

Beinfeld MC (2003). What we know and what we need to know about the role of endogenous CCK in psychostimulant sensitization. Life Sci 73: 643-654.

Bérod A, Rostène W (2002). Neurotensin: an endogenous psychostimulant? Curr Opin Pharmacol 2: 93-98.

Betancur C, Cabrera R, de Kloet R, Pélaprat D, Rostène W (1998). Role of endogenous neurotensin in the behavior and 
neuroendocrine effects of cocaine. Neuropsychopharmacology 19: $322-332$

Binder EB, Kinkead B, Owens MJ, Nemeroff CB (2001). Neurotensin and dopamine interactions. Pharmacol Rev 53: 453-486.

Blackburn A, Dewar K, Bauco P, Rompré PP (2004). Excitotoxic lesions of the prefrontal cortex attenuate the potentiation of amphetamine-induced locomotion by repeated neurotensin receptor activation. Brain Res 998: 184-193.

Borgland SL, Malenka RC, Bonci A (2004). Acute and chronic cocaine-induced potentiation of synaptic strength in the ventral tegmental area: electrophysiological and behavioral correlates in individual rats. $J$ Neurosci 24: 7482-7490.

Boudin H, Pélaprat D, Rostène W, Beaudet A (1996). Cellular distribution of neurotensin receptors in rat brain: immunohistochemical study using an antipeptide antibody against the cloned high affinity receptor. J Comp Neurol 373: 76-89.

Carraway R, Leeman SE (1973). The isolation of a new hypotensive peptide, neurotensin, from bovine hypothalamus. J Biol Chem 248: 6854-6861.

Costa FG, Frussa-Filho R, Felicio LF (2001). The neurotensin receptor antagonist, SR48692, attenuates the expression of amphetamine-induced behavioural sensitisation in mice. Eur J Pharmacol 428: 97-103.

Crombag HS, Badiani A, Chan J, Dell'Orco J, Dineen SP, Robinson TE (2001). The ability of environmental context to facilitate psychomotor sensitization to amphetamine can be dissociated from its effect on acute drug responsiveness and on conditioned responding. Neuropsychopharmacology 24: 680-690.

De Lima MS, de Oliveira Soares BG, Reisser AA, Farrell M (2002). Pharmacological treatment of cocaine dependence: a systematic review. Addiction 97: 931-949.

De Vries TJ, Shaham Y, Homberg JR, Crombag H, Schuurman K, Dieben J et al (2001). A cannabinoid mechanism in relapse to cocaine seeking. Nat Med 7: 1099-1100.

Dewey SL, Morgan AE, Ashby Jr CR, Horan B, Kushner SA, Logan J et al (1998). A novel strategy for the treatment of cocaine addiction. Synapse 30: 119-129.

Elliott PJ, Nemeroff CB (1986). Repeated neurotensin administration in the ventral tegmental area: effects on baseline and D-amphetamine-induced locomotor activity. Neurosci Lett 68: 239-244.

Ervin GN, Birkemo LS, Nemeroff CB, Prange Jr AJ (1981). Neurotensin blocks certain amphetamine-induced behaviors. Nature 291: 73-76.

Fantegrossi WE, Ko MCH, Woods JH, Richelson E (2005). Antinociceptive, hypothermic, hypotensive, and reinforcing effects of a novel neurotensin receptor agonist, NT69L, in rhesus monkey. Pharmacol Biochem Behav 80: 341-349.

Fatigati MD, Anderson RM, Rompré PP (2000). Effects of prefrontal cortex microinjection of neurotensin-(8-13) on midbrain dopamine and non-dopamine cell firing. Brain Res 876: $196-200$.

Ferrario CR, Gorny G, Crombag HS, Kolb B, Robinson TE (2005). Neural and behavioral plasticity associated with the transition from controlled to escalated cocaine use. Biol Psychiatry 58: 751-759.

Ford APDW, Marsden CA (1990). In vivo neurochemical and behavioural effects of intracerebrally administered neurotensin and D-Tryp11-neurotensin on mesolimbic and nigrostriatal dopaminergic function in the rat. Brain Res 534: 243-250.

Gawin FH (1991). Cocaine addiction: psychology and neurophysiology. Science 251: 1580-1586.

Gawin FH, Ellinwood Jr EH (1989). Cocaine dependence. Ann Rev Med 40: 149-161.

Geisler S, Bérod A, Zahm DS, Rostène W (2006). Brain neurotensin, psychostimulants, and stress-emphasis on neuroanatomical substrates. Peptides 27: 2364-2384.
Geisler S, Zahm DS (2006). Neurotensin afferents of the ventral tegmental area in the rat: (1) re-examination of their origins and (2) responses to acute psychostimulant and antipsychotic drug administration. Eur J Neurosci 24: 116-134.

Gendron L, Perron A, Payet MD, Gallo-Payet N, Sarret P, Beaudet A (2004). Low-affinity neurotensin receptor (NTS2) signaling: internalization-dependent activation of extracellular signalregulated kinases 1/2. Mol Pharmacol 66: 1421-1430.

Glimcher PW, Govino AA, Hoebel BG (1987). Neurotensin selfinjection in the ventral tegmental area. Brain Res 400: 147-150.

Glimcher PW, Margolin DH, Giovino AA, Hoebel BG (1984). Neurotensin: a new 'reward peptide'. Brain Res 291: 119-124.

Gully D, Canton M, Boigegrain R, Jeanjean R, Molimard JC, Poncelet $M$ et al (1993). Biochemical and pharmacological profile of a potent and selective neurotensin receptor antagonist. Proc Natl Acad Sci USA 90: 65-69.

Gully D, Labeeuw B, Boigegrain R, Oury-Donat F, Bachy A, Poncelet $M$ et al (1997). Biochemical and pharmacological activities of SR 142948A, a new potent neurotensin receptor antagonist. J Pharmacol Exp Ther 280: 802-812.

Horger BA, Taylor JE, Elsworth JD, Roth RH (1994). Preexposure to, but not cotreatment with, the neurotensin antagonist SR 48692 delays the development of cocaine sensitization. Neuropsychopharmacology 11: 215-222.

Jaffe JH, Cascella NG, Kumor KM, Scherer MA (1989). Cocaineinduced cocaine craving. Psychopharmacology 97: 59-64.

Kalivas PW, Duffy P (1990). Effect of acute and daily neurotensin and enkephalin treatments on extracellular dopamine in the nucleus accumbens. J Neurosci 10: 2940-2949.

Kalivas PW, Stewart J (1991). Dopamine transmission in the initiation and expression of drug- and stress-induced sensitization of locomotor activity. Brain Res Rev 16: 223-244.

Kinkead B, Nemeroff B (2002). Neurotensin: an endogenous antipsychotic? Curr Opin Pharmacol 2: 99-103.

Kitabgi P (2002). Targeting neurotensin receptors with agonists or antagonists for therapeutic purposes. Curr Opin Drug Discov Dev 5: 764-776.

Koob GF, Sanna PP, Bloom F (1998). Neuroscience of addiction. Neuron 21: 467-476.

Kreek MJ, LaForge KS, Butelman E (2002). Pharmacotherapy of addictions. Nat Rev 1: 710-726.

Li Y, Hu XT, Berney TG, Vartanian AJ, Stine CD, Wolf ME et al (1999). Both glutamate receptor antagonists and prefrontal cortex lesions prevent induction of cocaine sensitization and associated neuroadaptations. Synapse 34: 169-180.

Liu Q-S, Pu L, Poo M-M (2005). Repeated cocaine exposure in vivo facilitates LTP induction in midbrain dopamine neurons. Nature 437: 1027-1031.

Meltzer HY, Arvanitis L, Bauer D, Rein W, Meta-Trial Study Group (2004). Placebo-controlled evaluation of four novel compounds for the treatment of schizophrenia and schizoaffective disorders. Am J Psychiatry 161: 975-984.

Morgan AE, Porter SP, Clarkson FA, Volkow ND, Fowler JS, Dewey SL (1997). Direct approach for attenuating cocaine's effects on extracellular dopamine: targeting the dopamine transporter. Synapse 26: 423-427.

Mueller D, Stewart J (2000). Cocaine-induced conditioned place preference: reinstatement by priming injections of cocaine after extinction. Behav Brain Res 115: 39-47.

O'Brien MS, Anthony JC (2005). Risk of becoming cocaine dependent: epidemiological estimates for the United States, 2000-2001. Neuropsychopharmacology 30: 1006-1018.

Panayi F, Colussi-Mas J, Lambas-Senas L, Renaud B, Scarna H, Bérod A (2005). Endogenous neurotensin in the ventral tegmental area contributes to amphetamine behavioral sensitization. Neuropsychopharmacology 30: 871-879.

Panayi F, Dorso E, Lambas-Senas L, Renaud B, Scarna H, Bérod A (2002). Chronic blockade of neurotensin receptor reduces 
sensitized, but not acute, behavioral response to D-amphetamine. Neuropsychopharmacology 26: 64-74.

Pierce RC, Kalivas PW (1997). A circuitry model of the expression of behavioral sensitization to amphetamine-like psychostimulants. Brain Res Rev 25: 192-216.

Pilla M, Perachon S, Sautel F, Garrido F, Mann A, Wermuth CG et al (1999). Selective inhibition of cocaine-seeking behaviour by a partial dopamine D3 receptor agonist. Nature 400: 371-375.

Post RM, Rose H (1976). Increasing effect of repetitive cocaine administration in the rat. Nature 260: 731-732.

Radja F, Bauco P, Rompré PP (2006). Effects of excitotoxic lesions of the medial prefrontal cortex on density of high affinity [(125)I-Tyr3] neurotensin binding sites within the ventral midbrain and striatum. Eur J Pharmacol 539: 158-163.

Richelson E, Boules M, Fredrickson P (2003). Neurotensin agonists: possible drugs for treatment of psychostimulant abuse. Life Sci 73: 679-690.

Robinson TE, Berridge KC (1993). The neural basis of drug craving: an incentive-sensitization theory of addiction. Brain Res Rev 18: 247-291.

Rompré P, Perron S (2000). Evidence for a role of endogenous neurotensin in the initiation of amphetamine sensitization. Neuropharmacology 39: 1880-1892.

Rompré PP (1997). Repeated activation of neurotensin receptors sensitizes to the stimulant effect of amphetamine. Eur $J$ Pharmacol 328: 131-134.

Rompré PP, Bauco P (2006). Neurotensin receptor activation sensitizes to the locomotor stimulant effect of cocaine: a role for NMDA receptors. Brain Res 1085: 77-86.

Rompré PP, Boye SM, Moisan J (1998). Activation of neurotensin receptors in the prefrontal cortex stimulates midbrain dopamine cell firing. Eur J Pharmacol 341: 169-172.

Rostène W, Azzi M, Boudin H, Lépée I, Souazé F, Mendez-Ubah M et al (1998). Use of nonpeptide antagonists to explore the physiological roles of neurotensin. Ann NY Acad Sci 814: 125-140.

Santucci V, Gueudet C, Steinberg R, Le Fur G, Soubrié P (1997). Involvement of cortical neurotensin in the regulation of rat meso-cortico-limbic dopamine neurons: evidence from changes in the number of spontaneously active A10 cells after neurotensin receptor blockade. Synapse 26: 370-380.
Sarnyai Z, Shaham Y, Heinrichs SC (2001). The role of corticotropin-releasing factor in drug addiction. Pharmacol Rev 53: 209-243.

Sarret P, Gendron L, Kilian P, Nguyen HM, Gallo-Payet MD, Beaudet A (2002). Pharmacology and functional properties of NTS2 neurotensin receptors in cerebellar granule cells. J Biol Chem 277: 36233-36243.

Soares BG, Reisser AA, Farrell M (2003). Dopamine agonists for cocaine dependence. Cochrane Database Syst Rev 2003: CD003352.

Sotty F, Soulière F, Brun P, Chouvet G, Steinberg R, Soubrié P et al (1998). Differential effects of neurotensin on dopamine release in the caudal and rostral nucleus accumbens: a combined in vivo electrochemical and electrophysiological study. Neuroscience 85: 1173-1182.

Stewart J (2000). Pathways to relapse: the neurobiology of drugand stress-induced relapse to drug-taking. J Psychiatry Neurosci 25: $125-136$.

Tzschentke TM (2000). The medial prefrontal cortex as a part of the brain reward system. Amino Acids 19: 211-219.

Valverde O, Smadja C, Roques BP, Maldonado R (1997). The attenuation of morphine-induced place preference following chronic mild stress is reversed by a $\mathrm{CCK}_{\mathrm{B}}$ receptor antagonist. Psychopharmacology 131: 79-85.

an den Brink W, van Ree JM (2003). Pharmacological treatments for heroin and cocaine addiction. Eur Neuropsychopharmacol 13: 476-487.

Vanderschuren LJ, Kalivas PW (2000). Alterations in dopaminergic and glutamatergic transmission in the induction and expression of behavioral sensitization: a critical review of preclinical studies. Psychopharmacology 151: 99-120.

Vezina P, Lorrain DS, Arnold GM, Austin JD, Suto N (2002). Sensitization of midbrain dopamine neuron reactivity promotes the pursuit of amphetamine. J Neurosci 22: 4654-4662.

Vita N, Oury-Donat F, Chalon P, Guillemot M, Kaghat M, Bachy A et al (1998). Neurotensin is an antagonist of the human neurotensin NT2 receptor expressed in Chinese hamster ovary cells. Eur J Pharmacol 360: 265-272.

Yamada M, Lombet A, Forgez P, Rostene W (1998). Distinct functional characteristics of levocabastine sensitive rat neurotensin NT2 receptors expressed in Chinese Hamster Ovary cells. Life Sci 62: 375-380. 